International Journal of Engineering \& Technology, $7(4.11)(2018) 241-245$
International Journal of Engineering \& Technology
SPC
Website: www.sciencepubco.com/index.php/IJET
Research paper

\title{
Development of Boost Inverter Using Single Phase Matrix Converter Topology
}

\author{
M.F. Mohd Zin, R. Baharom*, I. Mohd Yassin \\ Faculty of Electrical Engineering, Universiti Teknologi MARA, 40450 Shah Alam, Selangor, Malaysia \\ *Corresponding author E-mail: rahimi6579@gmail.com
}

\begin{abstract}
This paper presents the development of boost inverter using a single phase matrix converter (SPMC). A new switching algorithm was developed to control the SPMC circuit topology to operate as a boost inverter. The pulse width modulation (PWM) technique was used to calculate the switching duty ratio to synthesize the output. As part of boost inverter operation, a safe-commutation switching algorithm has been applied to avoid the voltage and current spikes due to the effect of inductive loads. The simulation of the proposed converter was carried out in MATLAB/SIMULINK. Selected simulation are presented to verify the proposed operation.
\end{abstract}

Keywords: Single Phase Matrix Converter (SPMC); Inverter; Safe-Commutation Strategy; Boost Inverter; Pulse width modulation (PWM).

\section{Introduction}

DC-AC converter (also known as inverter) is used to change the input $\mathrm{DC}$ voltage into the output $\mathrm{AC}$ voltage. The inverter produces an AC voltage from DC power sources and is important for powering electronics and electrical equipment rated at the $\mathrm{AC}$ mains voltage. Direct current is very beneficial in daily life, but batteries can generally only provide low voltage DC power [1-2]. Nowadays, there are numerous devices that need more power to function properly more than what DC can provide. Mostly, the devices are designed to run on the $120 \mathrm{~V}$ or $230 \mathrm{~V}$ AC power [3]. Based on this situation, the inverter is very functional to generate the AC power from the DC source so that the power can being supplied to the AC load.

The circuit topology of an inverter are divided into two types, which are inverter based upon frequency and inverter based upon output waveforms [4]. The inverter based upon frequency are based on high frequency and low frequency while the inverter based upon output waveform can be divide into three groups which are square wave, modified sine wave and the pure sine wave [5].

A boost inverter is a DC-AC converter that step up the voltage level and at the same time, reducing the current level that flows to the load [6]. The boost inverter is used as a step up the generated output voltage, so that it is able to provide the higher power into an AC load without the use of heavy and bulky transformer, thus reduces the cost and power loss [7].

In this paper, a new boost inverter circuit topology is proposed to solve the problem faced by conventional boost inverters in terms of power density and power loss [8]. The potential application of the proposed boost inverter are in photovoltaic system, uninterruptible power supply and also as a standalone boost inverter.

\section{Principle DC To AC Operation Using SPMC}

Fig. 1 and Fig. 2 show the SPMC circuit topology required four bi-directional switches [14-17].

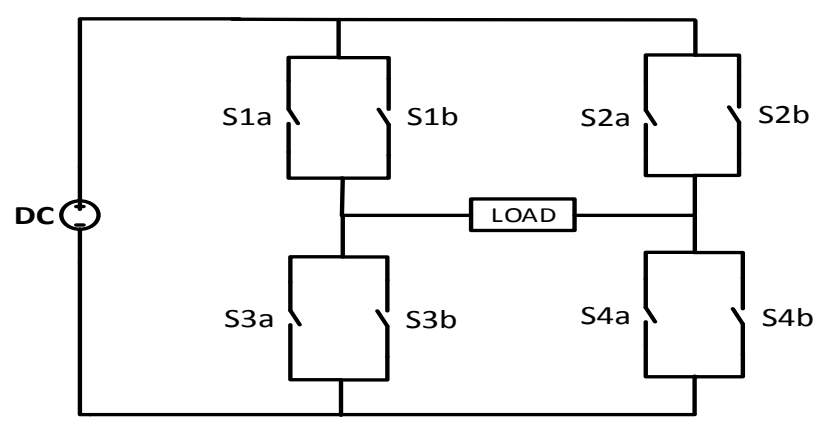

Fig. 1: The SPMC circuit topology

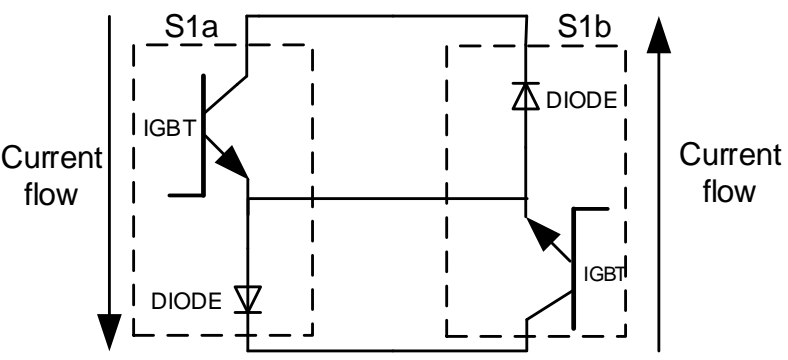

Fig. 2: Common Emitter Configuration

The design parameters of the proposed converter are as tabulated in Table 1. The switching strategy implemented in SPMC for basic inverter operation is as shown in Table 2. Fig. 3 shows the switching algorithm for basic inverter operation. During positive cycle operation, a PWM signal is controlled by switches S1a and 
S4a whilst during the negative cycle operation, the switch S2a and S3a acts as controller of PWM signal [8]. Fig. 4(a) and Fig. 4(b) show the illustration of the principle operation of DC-AC converter for positive cycle and negative cycle respectively.

Table 1: Design parameters

\begin{tabular}{|c|c|}
\hline Supply voltage, $\mathrm{V}_{\mathrm{s}}$ & $12 \mathrm{~V}$ \\
\hline Switching frequency, $\mathrm{f}_{\mathrm{s}}$ & $2 \mathrm{kHz}$ \\
\hline Load resistor, $\mathrm{R}$ & $50 \Omega$ \\
\hline Modulation index, $\mathrm{m}_{\mathrm{a}}$ & 0.5 \\
\hline
\end{tabular}

Table 2: Switching Algorithm of principle DC-AC operation

\begin{tabular}{|c|c|c|}
\hline \multirow{2}{*}{ Switches } & \multicolumn{2}{|c|}{ Operations } \\
\cline { 2 - 3 } & Positive Cycle & Negative Cycle \\
\hline S1A & off & pwm \\
\hline S1B & off & off \\
\hline S2A & pwm & off \\
\hline S2B & off & off \\
\hline S3A & pwm & off \\
\hline S3B & off & off \\
\hline S4A & off & pwm \\
\hline S4B & off & off \\
\hline
\end{tabular}

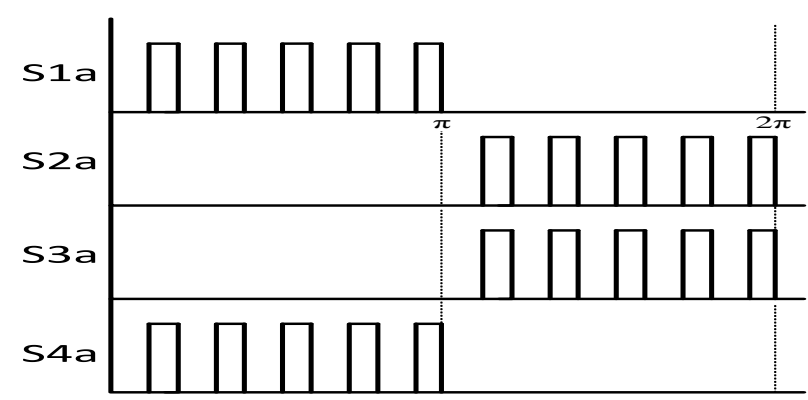

Fig. 3: Switching algorithm for principle DC-AC operation (a)

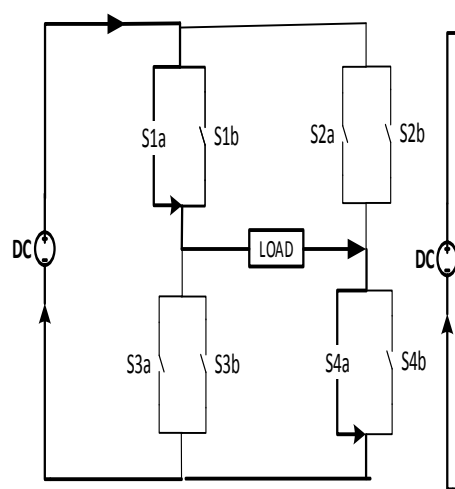

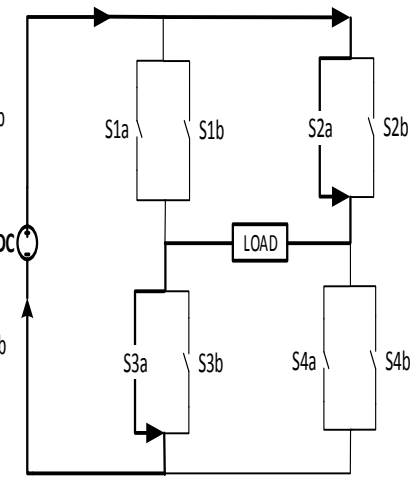

Fig. 4: (a) Positive and (b) Negative half cycle operation

\subsection{Inverter Operation with Safe-Commutation Strate- gy}

The proposed safe-commutation strategy is used to solve the spikes problem due to the used of inductive load [18] without additional snubber circuit [12]. An arrangement of the switching mode of operation for the safe-commutation strategy is as tabulated in Table 3. The PWM is function to control the power by the switching scheme with a fixed switching frequency. In this operation, three switches were used for every cycle as each switch will operates either as commutation switch or power controller. Fig. 5 shows the switching algorithm for inverter operation with safecommutation strategy. During the positive half cycle operation, the switch S1a is controlled by the PWM while switches S3b and S4a operated as commutation switches. During the negative half cycle operation, the switch S2a is controlled by the PWM signal. Then, both switches S3a and S4b were operated as commutation switches.
Table 3: Switching Algorithm for DC-AC with safe-commutation operation

\begin{tabular}{|c|c|c|}
\hline \multirow{2}{*}{ Switches } & \multicolumn{2}{|c|}{ Operations } \\
\cline { 2 - 3 } & Positive Half Cycle & Negative Half Cycle \\
\hline S1A & off & pwm \\
\hline S1B & off & off \\
\hline S2A & pwm & off \\
\hline S2B & off & off \\
\hline S3A & on & off \\
\hline S3B & off & on \\
\hline S4A & off & on \\
\hline S4B & on & off \\
\hline
\end{tabular}

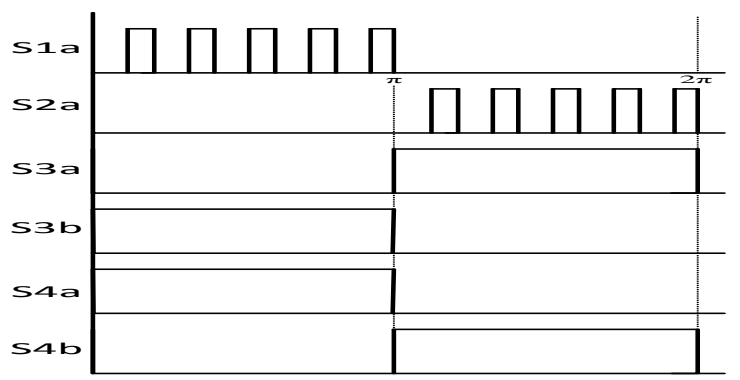

Fig. 5: Switching algorithm of DC-AC operation with safe-commutation strategy

\subsection{Boost DC to AC Operation}

The operation of the boost inverter was designed to produce the output voltage higher than input. Thus, an additional inductor is used as an energy storage before this energy transferred to the load. Fig. 6 shows the switching algorithm for boost inverter operation. The proposed of switching algorithm for boost inverter is as shown in Table 4. The circuit operation for boost inverter using SPMC is proposed as below [11]:

[1] Mode 1 (positive half cycle): The current from the positive DC supply will flow through switches S1a and S3a. Thus, the inductor, L will be charged. The switch S3a is controlled by PWM signals shown in Fig. 7(a).

[2] Mode 2 (positive half cycle): The current flows through S1a and S4a. Hence, energy from the inductor will be transferred to the load as shown in Fig. 7(b).

[3] Mode 3 (negative half cycle): The current flows through S1a and S4a. During this mode operation, the inductor, $\mathrm{L}$ will be charged. The switch S4a is controlled by PWM signal as shown in Fig. 7(c).

[4] Mode 4 (negative half cycle): The current flows through S2a and S3a. During this mode operation, energy from the inductor will be transferred to the output as illustrated in Fig. 7(d).

Table 4: Switching Algorithm for Boost DC-AC operation

\begin{tabular}{|c|c|c|}
\hline \multirow{2}{*}{ Switches } & \multicolumn{2}{|c|}{ Operations } \\
\cline { 2 - 3 } & Positive Cycle & Negative Cycle \\
\hline S1A & pwm & on \\
\hline S1B & off & off \\
\hline S2A & pwm & off \\
\hline S2B & off & off \\
\hline S3A & on & pwm \\
\hline S3B & off & off \\
\hline S4A & off & pwm \\
\hline S4B & off & off \\
\hline
\end{tabular}

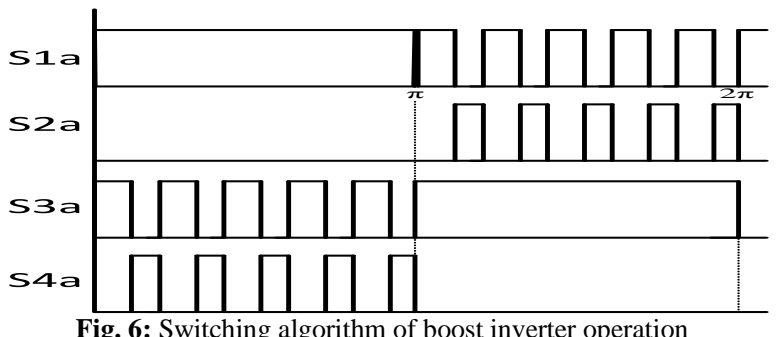




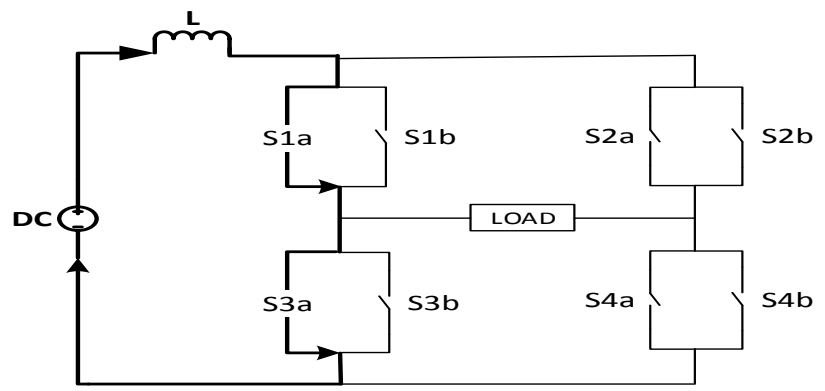

(a)

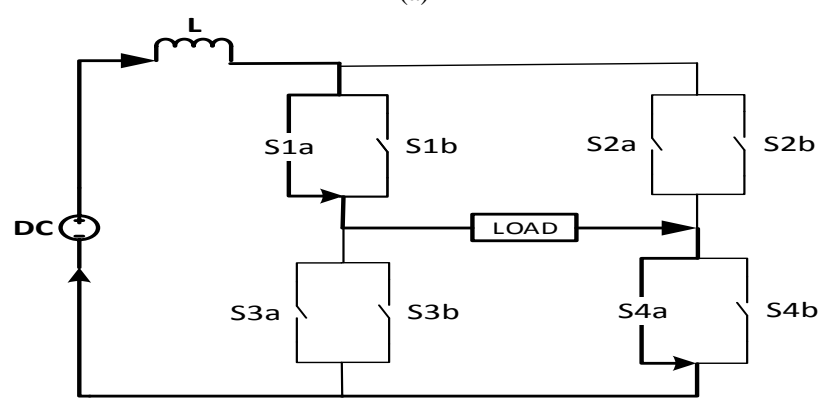

(b)

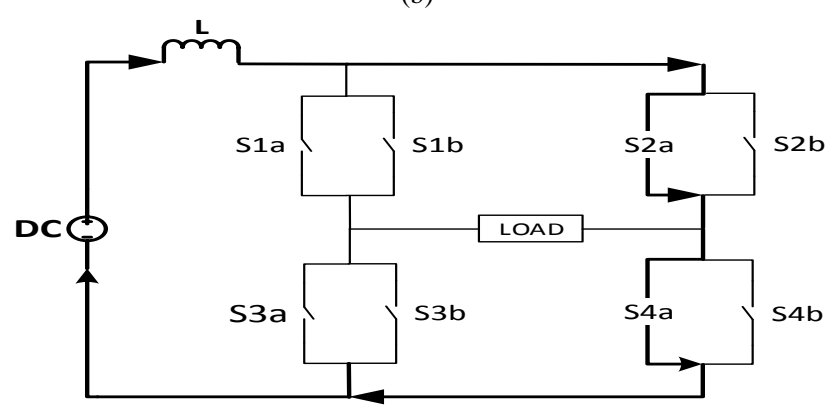

(c)

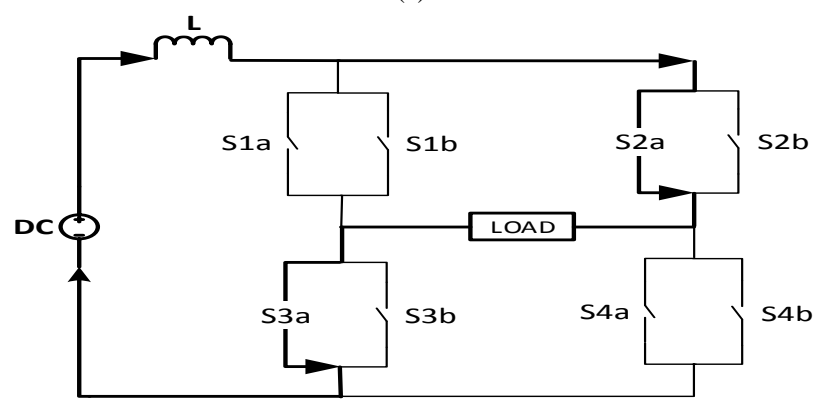

(d)

Fig. 7: Switching algorithm of Boost DC-AC operation (a) Mode 1, (b) Mode 2, (c) Mode 3 and (d) Mode 4

\section{Computer Simulation Model}

The computer simulation model using MATLAB/Simulink was developed to investigate the operation of boost inverter circuit topology. In the main circuit of SPMC consists of eight IGBTs arranged in the common emitter configuration [16]. The boost inverter were operated with $12 \mathrm{VDC}$ supply and resistive and inductive load, $50 \mathrm{Ohm}$ and $10 \mathrm{mH}$ respectively including $10 \mathrm{mH}$ of additional boost inductor. The value of modulation index was fixed to 0.5 at $2 \mathrm{kHz}$ of switching frequency [16].

Fig. 8 to 12 show the computer simulation model of the inverter using SPMC. In order to produce clarity model of the inverter using SPMC, the subsystem is used to reduce the complexities of the main circuit model [13]. Fig. 9 shows the circuit topology of the SPMC. It consists four bidirectional switches. Fig. 10 shows the bidirectional switches connected with common emitter configuration. Fig. 11 and Fig. 12 show the model of controller circuit implemented for the operation of DC-AC converter with safe commutation strategy.

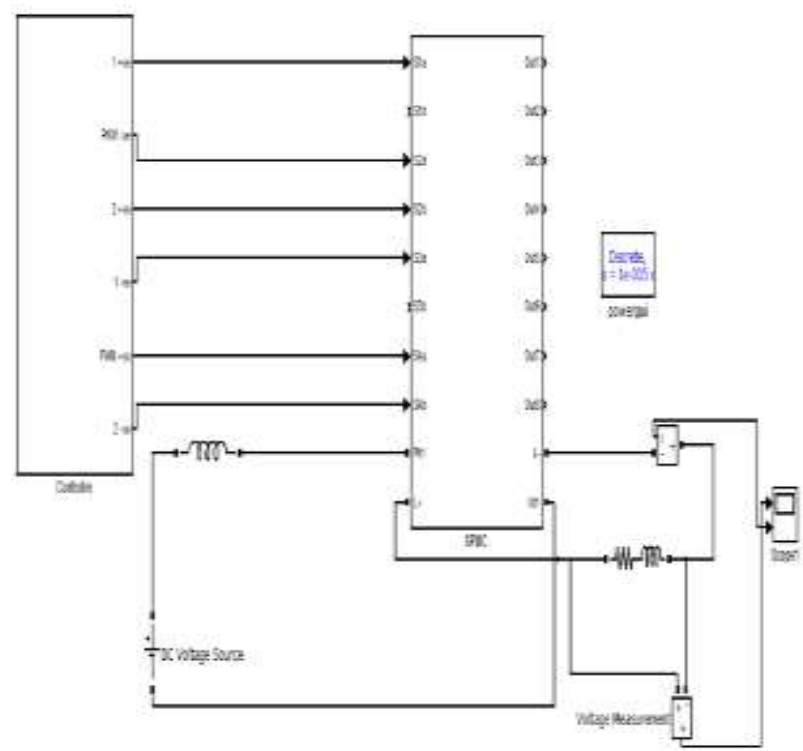

Fig. 8: The boost DC-AC converter

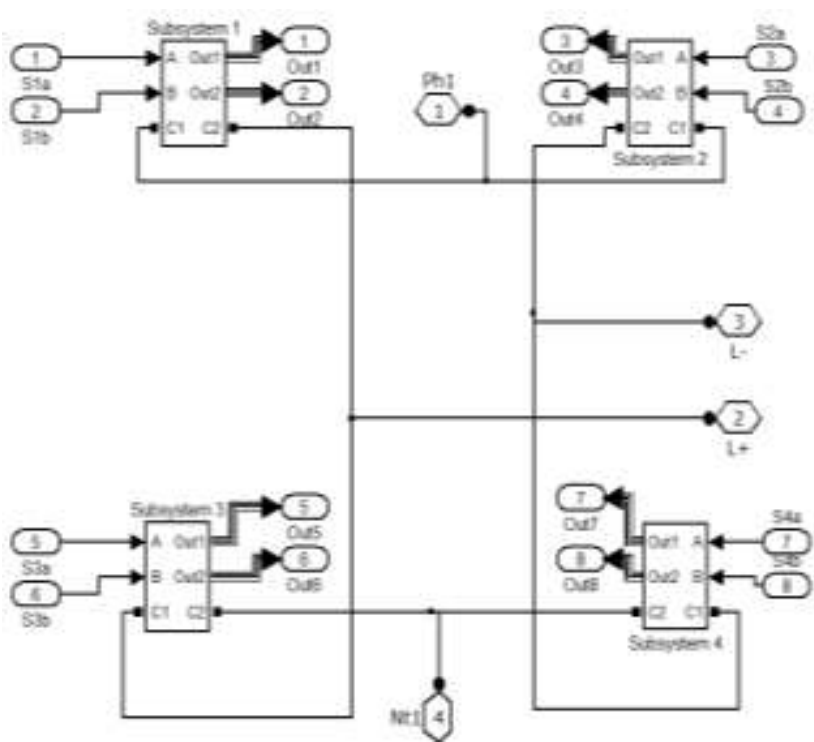

Fig. 9: SPMC circuit model

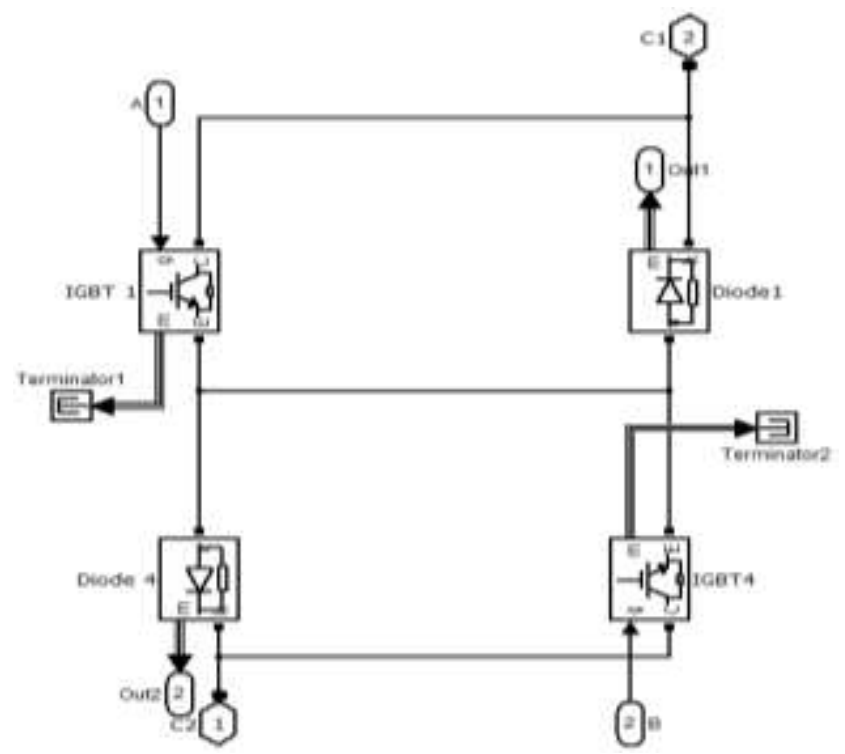

Fig. 10: Bi-directional switch model 

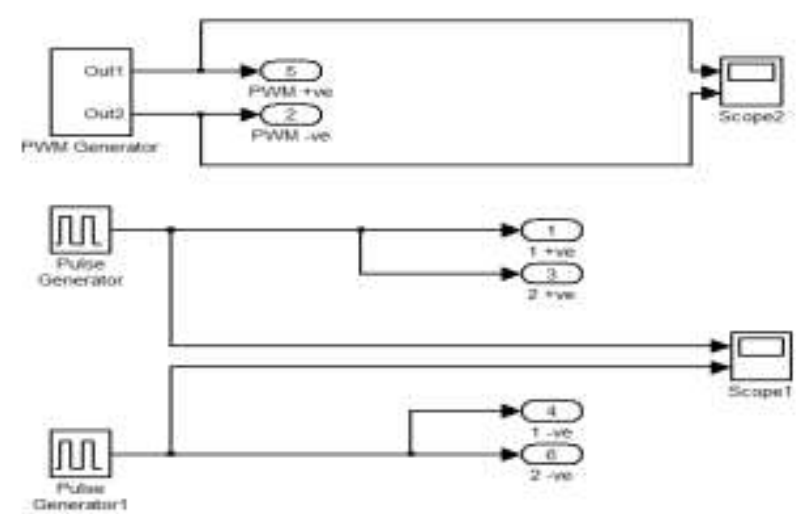

Fig. 11: Model of controller circuit

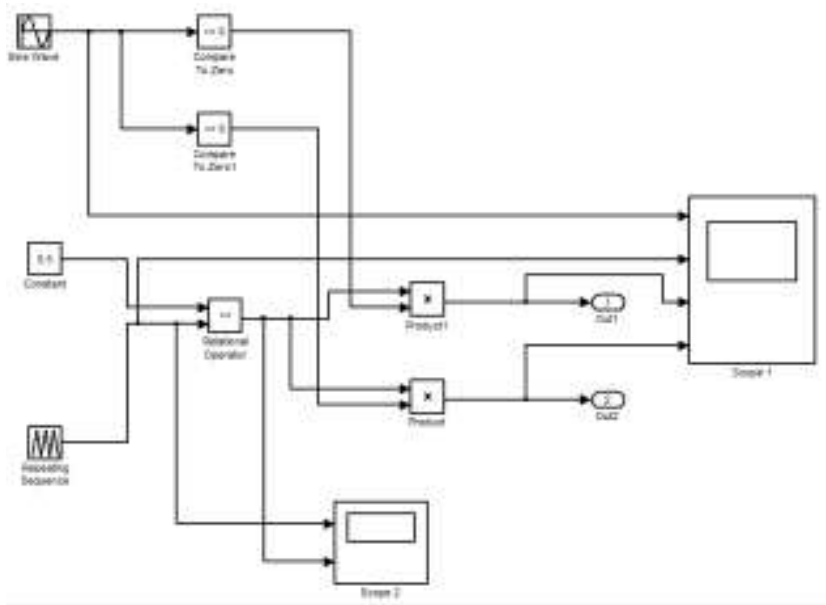

Fig. 12: PWM Generator

\section{Results and Discussion}

\subsection{Principle DC-AC Operation with a Resistive Load}

The simulation result of input voltage for basic inverter operation is as shown in Fig. 13. The waveform shows that the input source is from DC source which is $12 \mathrm{~V}_{\mathrm{DC}}$. After the operation of inverter using SPMC topology being applied, the results of the output voltage and current produced is in AC forms. Fig. 14 shows the simulation result of the output voltage. It is clearly show that the input voltage is in a DC form, whilst the output voltage is in an AC forms, hence proved the inverter operation.

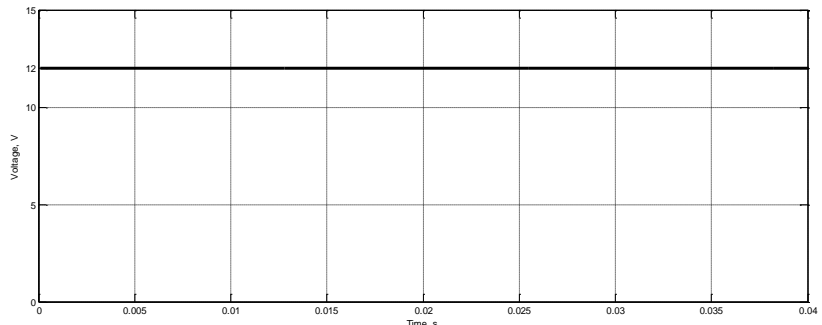

Fig. 13: Input DC voltage

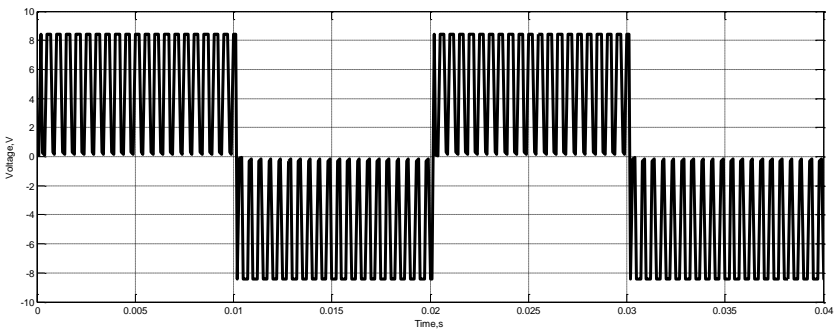

Fig. 14: Output AC voltage

\subsection{DC-AC Operation with Inductive Load without Safe-Commutation Strategy}

Fig. 15 and Fig. 16 show the results for the operation of an inverter using SPMC without safe-commutation technique. The spikes occurs in the output voltage waveform and can affect the efficiency of electrical equipment [19]. The maximum voltage spikes that has been recorded from the simulation is about $12.38 \mathrm{~V}$. The result shows due to the presence of an inductive load, induces the voltage spikes.

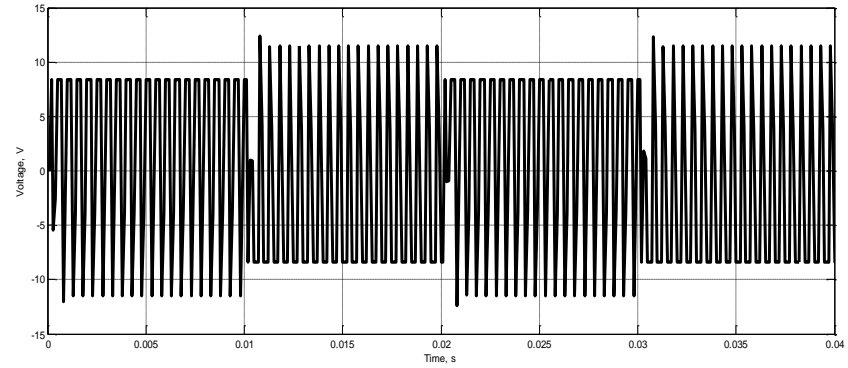

Fig. 15: Output voltage without safe-commutation strategy

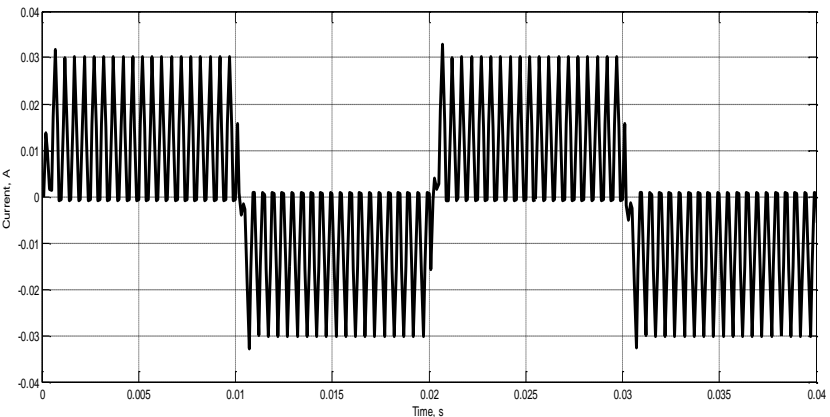

Fig. 16: Output current without safe-commutation

\subsection{DC-AC Operation with Safe-Commutation Strategy}

Fig. 17 and Fig. 18 show the waveforms for the output voltage and current after the implementation of safe-commutation technique. The results show that the voltage spikes has been successfully eliminated and prove that the proposed safe-commutation algorithm is affected.

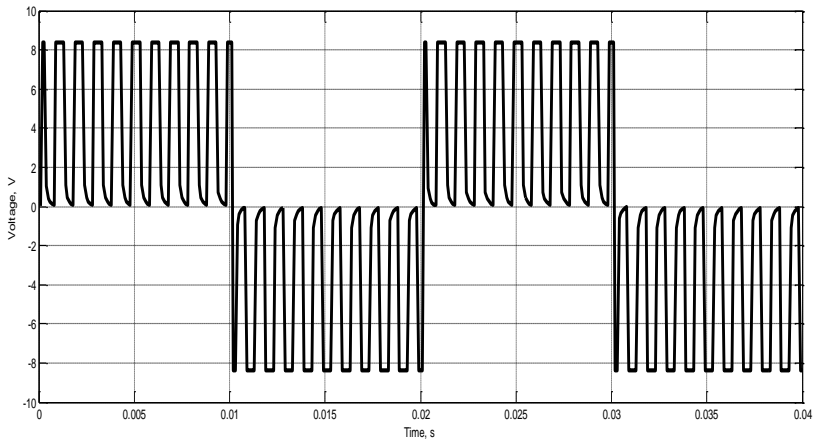

Fig. 17: Output voltage with safe commutation

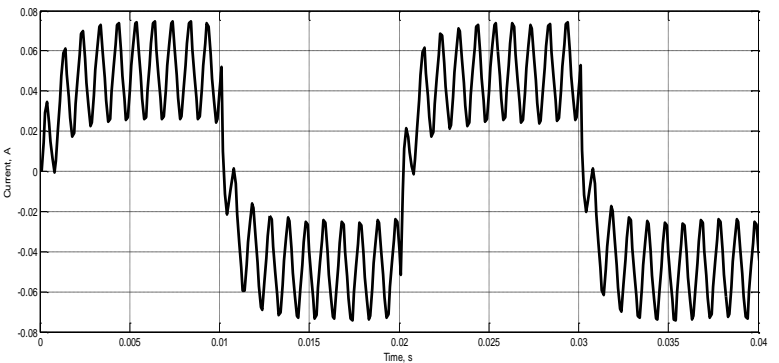

Fig. 18: Output current with safe-commutation 


\subsection{Boost DC-AC Operation with Safe-Commutation Strategy}

The results of boost inverter operation are shown in Fig. 19 and Fig. 20. From the simulation result, the output voltage increase from $12 \mathrm{~V}_{\mathrm{DC}}$ to the $18.72 \mathrm{~V}_{\mathrm{AC}}$. The value of modulation index have been varied to study the effect on the output voltage. Table 5 shows the maximum output voltage can be produced with the maximum value of modulation index, while the value of inductance is fixed as $10 \mathrm{mH}$. Fig. 21 shows the results of modulation index versus maximum output voltage. It is clearly shows that the output voltage increases by the increase of modulation index.

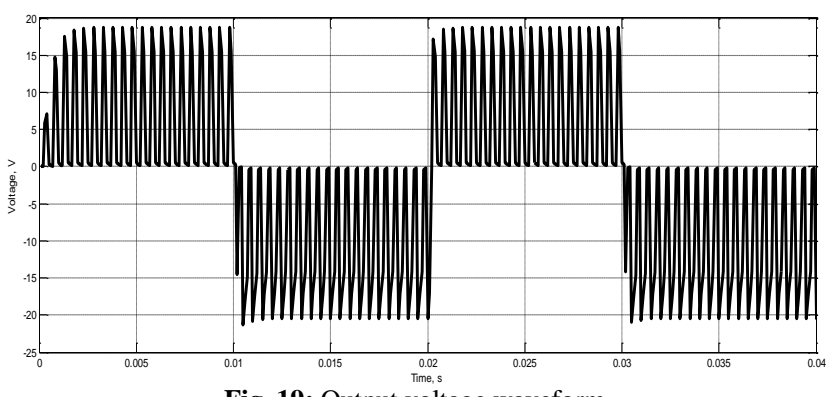

Fig. 19: Output voltage waveform

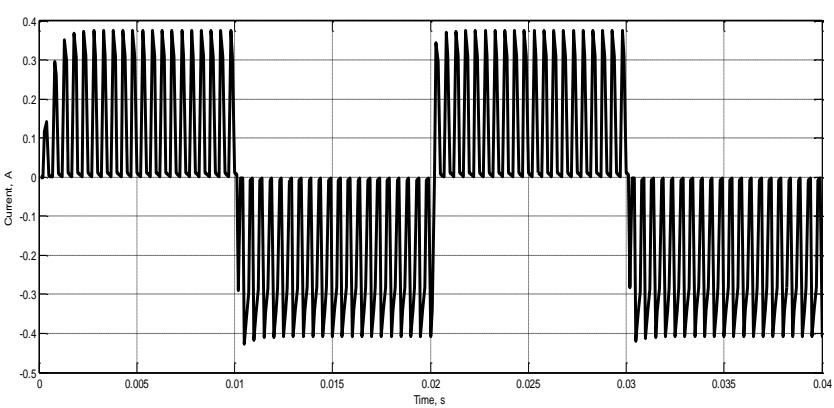

Fig. 20: Output current waveform

Table 5: Modulation index versus maximum output voltage

\begin{tabular}{|c|c|}
\hline Modulation Index & Maximum Output Voltage (V) \\
\hline 0.1 & 10 \\
\hline 0.5 & 21 \\
\hline 0.9 & 86 \\
\hline
\end{tabular}

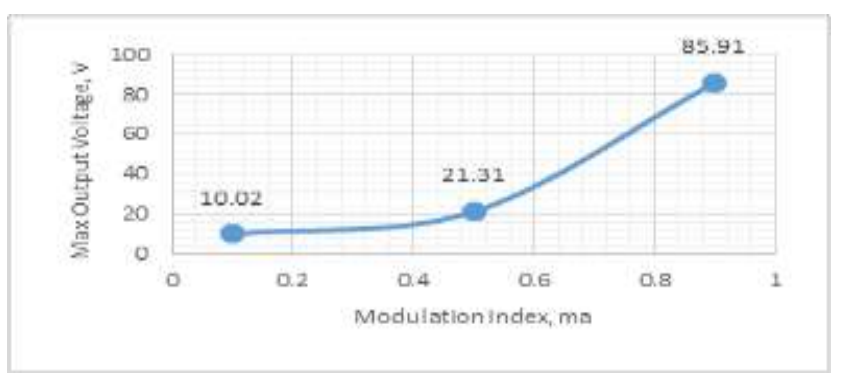

Fig. 21: Modulation index versus maximum output voltage

\section{Conclusion}

For the inverter operation without safe-commutation strategy, the result illustrates the effect of inductive load to the output waveform when the spikes occurs. While, with the proposed safecommutation strategy, the spikes was successfully eliminated and prove that the proposed safe-commutation algorithm is affected. For the boost inverter operation, the proposed new switching algorithm is successful when the result shows that the output voltage is greater than the input. The proposed boost inverter operation can simplify the conventional power electronics converter that use the transformer in order to step-up the AC voltage level, resulting in improved the power density, hence the reduction of the total power loss.

\section{Acknowledgement}

Authors gratefully acknowledge the financial support from Ministries of Higher Education Malaysia and Institute of Research Management and Innovation (IRMI) Universiti Teknologi MARA Grant No: 600-RMI/NRGS 5/3 (3/2013).

\section{References}

[1] R. Shankar, R. Sankarganesh, and S. Ramesh, "Design and simulation of switched boost inverter for AC and DC loads," 3(1), 946-954, 2014

[2] P. Deivasundari and V. Jamuna, "Single phase matrix converter as an "all silicon solution," Proceedings of the 1st Int. Conf. Electr. Energy Syst., pp. 86-91, 2011

[3] P. Sanchis; A. Ursaea; E. Gubia; L. Marroyo "Boost DC-AC inverter: A new control strategy," IEEE Trans. Power Electron., 20(2), 343-353, 2005.

[4] T. Liang, J. Shyu, and J. Chen, "A novel DC/AC boost inverter", Proceedings of the 37th Intersociety Energy Conversion Engineering Conference, pp. 629-634, 2002.

[5] R. Patil, "Single phase to three phase AC matrix converter for traction drives," IOSR J. Electr. Electron. Eng., 10(2), 2278-1676, 2015.

[6] R. M. Anusuya and R. Saravanakumar, "Modeling and simulation of a single phase matrix converter with reduce switch count as a buck / boost rectifier with close loop control," Special Issue of IJCCT, 3(1), 93-99, 1997.

[7] R. Caceres and I. Barbi, "A boost DC-AC converter: Operation, analysis, control and experimentation," Proceedings of the IEEE 21st Annu. Conf Ind. Electron., pp. 546-551, 1995.

[8] S. Chawda, "Analysis of single phase matrix converter," International Journal of Engineering Research and Applications, 4(3), 856-861, 2014.

[9] Minh-Khai Nguyen; Tan-Tai Tran; Young Cheol Lim, "A family of PWM control strategies for single-phase quasi-switched-boost inverter", IEEE Transactions on Power Electronics, 2018, 1-11, 2018.

[10] R. Baharom, N. R. Hamzah, and M. K. Hamzah, "Advanced singlephase AC-DC converter using single-phase matrix converter topology," Proceedings of the Int. Conf. Electr. Control Comput. Eng., pp. 33-38, 2011.

[11] V. Satish, S. K. Konathala, and A. U. R. Kiran, "Design and implementation of single phase matrix converter for cycloconverter operation," International Journal of Engineering, 3(1), 922-927, 2014.

[12] R. Baharom, N. R. Hamzah, and M. K. Hamzah, "A new safecommutation technique for AC-DC converter operation using singlephase matrix converter," Proceedings of the IEEE Int. Conf. Power Energy, no. December, pp. 298-302, 2012.

[13] S. Z. M. Noor, M. K. Hamzah, R. Baharom, and N. Y. Dahlan, "A new single-phase inverter with bidirectional capabilities using single-phase matrix converter," Proceedings of the IEEE Annu. Power Electron. Spec. Conf., pp. 464-470, 2007.

[14] Z. Idris, S. Z. Mohammad Noor, and M. K. Hamzah, "Safe commutation strategy in single phase matrix converter," Proceedings of the Int. Conf. Power Electron. Drives Syst., pp. 886-891, 2005.

[15] R. Baharom, M. K. Hamzah, A. Saparon, and N. R. Hamzah, "Singlephase matrix converter operating as buck and boost rectifier," Proceedings of the 4th IEEE Conf. Ind. Electron. Appl., pp. 3338-3342, 2009.

[16] A. S. Shilpa and H. V. K. Shetty, "Switched boost inverter with PWM control and development of a prototype model," International Journal of Advanced Research in Electrical, Electronics and Instrumentation Engineering, 3(8), 10978-10986, 2014.

[17] R. Adda, S. Mishra, and A. Joshi, "A PWM control strategy for switched boost inverter," Proceedings of the IEEE Energy Conversion Congress and Exposition, pp. 991-996, 2011.

[18] S. Z. Mohammad Noor, R. Baharom, N. S. Damanhuri, and M. K. Hamzah, "Single-phase inverter with fully controllable regenerative capabilities using single-phase matrix converter," Proceedings of the 3rd IEEE Conf. Ind. Electron. Appl., pp. 934-939, 2008.

[19] S. Z. M. Noor, R. Baharom, M. K. Hamzah, and N. R. Hamzah, "Safecommutation strategy for controlled rectifier operation using singlephase matrix converter," Proceedings of the Int. Conf. Power Electron. Drive Syst., pp. 1026-1029, 2009.

[20] B. Kalaivani, V. K. Chinnaiyan, J. Jerome, "A novel control strategy for the boost DC - AC inverter", Proceedings of the IEEE India International Conference on Power Electronics, pp. 341-344, 2006. 